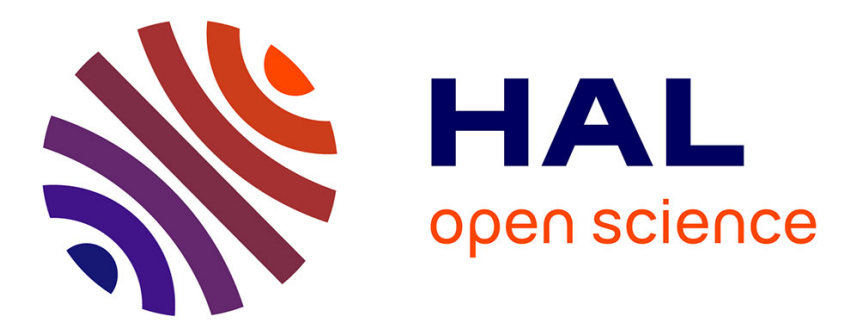

\title{
How olive pomace can be valorized as fillers to tune the biodegradation of PHBV based composites
}

\author{
Sarah Lammi, Emmanuelle Gastaldi, Fabrice Gaubiac, Helene
}

Angellier-Coussy

\section{- To cite this version:}

Sarah Lammi, Emmanuelle Gastaldi, Fabrice Gaubiac, Helene Angellier-Coussy. How olive pomace can be valorized as fillers to tune the biodegradation of PHBV based composites. Polymer Degradation and Stability, 2019, 166, pp.325-333. 10.1016/j.polymdegradstab.2019.06.010 . hal-02627990

\section{HAL Id: hal-02627990 \\ https: / hal.inrae.fr/hal-02627990}

Submitted on 25 Oct 2021

HAL is a multi-disciplinary open access archive for the deposit and dissemination of scientific research documents, whether they are published or not. The documents may come from teaching and research institutions in France or abroad, or from public or private research centers.
L'archive ouverte pluridisciplinaire HAL, est destinée au dépôt et à la diffusion de documents scientifiques de niveau recherche, publiés ou non, émanant des établissements d'enseignement et de recherche français ou étrangers, des laboratoires publics ou privés.

\section{(c) (1) $\$$}

Distributed under a Creative Commons Attribution - NonCommercial| 4.0 International 
1 How olive pomace can be valorized as fillers to tune the biodegradation of PHBV based

composites

Sarah Lammi ${ }^{1,2}$, Emmanuelle Gastaldi ${ }^{1}$, Fabrice Gaubiac ${ }^{1}$, Hélène Angellier-Coussy ${ }^{1 *}$

${ }^{1}$ JRU IATE 1208 - CIRAD/INRA/Montpellier SupAgro/University of Montpelier, 2 place Pierre Viala, F-34060 Montpellier, France

${ }^{2}$ Department of Agronomic Sciences, University of Mouloud MAMMERI, BP 17, 15000 Tizi-Ouzou, Algeria.

*Corresponding author: helene.coussy@umontpellier.fr

\section{Abstract}

Polyhydroxybutyrate-co-valerate (PHBV) is a very promising bio-sourced and biodegradable bacterial polyester, the commercial development of which being limited by its high cost. On the other hand, olive oil extraction generates a large amount of lignocellulosic solid residue, called olive pomace (OP), whose disposal raises environmental concerns, including the inhibition of soil microbial populations and the reduction of seed germination. To address these issues, PHBV/OP based biocomposites were produced (at a filler content of $15 \mathrm{wt} \%$ ) using three different fillers obtained by dry fractionation of OP, i.e. a stone-rich fraction (SF), a pulp-rich fraction (PF) and a crude pomace (F0). The objective of the present work was to investigate how the composition of OP-based fillers influenced the biodegradability of resulting biocomposites. The biodegradation of PHBV, OP-based fillers and OP/PHBV-based biocomposites was assessed by respirometric tests conducted in a standardized soil environment over 4 months. Results showed that the incorporation of OP-based fillers in PHBV favored the overall biodegradability of the materials. Indeed, 100\% of biodegradation was achieved after 75, 79 and 87 days for PHBV-F0, PHBV-SF and PHBV-PF formulations 
respectively, while a biodegradation rate of only $91 \%$ was obtained after 123 days in the case of neat PHBV. These results were discussed in the light of several parameters such as the material structure, the affinity of the fillers for the matrix, the composition and the degree of crystallinity of the filler, together with the antibacterial activity of the OP samples assessed by a direct contact technique on solid medium.

Keywords: Biodegradation; biocomposites; PHBV; olive pomace; soil; packaging; respirometric tests.

\section{Introduction}

Most of currently used synthetic polymers are produced from petrochemicals and are not biodegradable. Persistent polymers generate long-term negative impacts on environment and human health, due to their accumulation in the environment and to the diffusion of degraded plastic micro- and nano-particles towards the soil, the water and finally living organisms. That is why bio-sourced polymers that are fully biodegradable in natural conditions have raised great interest, particularly for short-term applications such as packaging and agriculture (Avérous and Pollet, 2012). It is worth noting that food packaging and agriculture sectors represent the largest plastic consumption sectors, with respectively $40 \%$ and $5 \%$ of the total consumption, and more than $75 \%$ of uncollectable and dispersed plastics.

Biodegradation is a process in which the molecular structure of materials is broken down through metabolic or enzymatic mechanisms. The decomposition process occurs via enzymes secreted by naturally occurring microorganisms such as bacteria, fungi or actinomycetes. Biodegradation can occur in aerobic (requiring oxygen) or anaerobic (without oxygen) conditions. Biomass (humus, compost) and gas (carbon dioxide and methane) are the main products of a biodegradation process, carbon dioxide being generated under aerobic conditions while in the case of anaerobic conditions methane was mainly produced (Andrady, 
2011; Kumar et al., 2013; Stoleru, 2017). Besides surface properties (surface area, hydrophilic/ hydrophobic properties, roughness) other intrinsic chemical and physical factors are involved in the biodegradation of polymers like, first order structures (chemical structure, molecular weight and molecular weight distribution) and higher order structures (glass transition temperature, melting temperature, modulus of elasticity, crystallinity and crystal structure) (Tokiwa et al., 2009). The degree of crystallinity is a crucial factor affecting biodegradability, since enzymes mainly attack the amorphous domains of a polymer where polymer chains are loosely packed, and are thus more susceptible to degradation. The crystalline parts of the polymers are generally more resistant to biodegradation than the amorphous ones. Aliphatic polyesters [ester bond (-CO-O-)] are typical polymers that show high potential for use as biodegradable plastics, owing to their susceptibilities to lipolytic enzymes and microbial degradation (Tokiwa et al., 2009).

Among the bio-sourced polymers able to biodegrade in natural conditions, polyhydroxyalkanoates (PHAs) are a class of polyesters that present the advantage to be naturally produced by a wide variety of bacteria able to accumulate from 30 to $80 \%$ of their dry weight in the form of intracellular granules as carbon and energy reserves (Madison and Huisman, 1999; Singh Saharan et al., 2014). The copolymer poly(3-hydroxybutyrate-co-3hydroxyvalerate) (PHBV) is one of the most well-known PHA since already commercially available for the production of disposable items and food packaging materials (Kourmentza et al., 2017). However, as compared to conventional plastics, PHBV is still more expensive (around $5 € / \mathrm{kg}$ ), which limits its use to a narrow range of applications. To decrease the overall cost of materials while modulating their functional properties and maintaining their biodegradability, the incorporation of lignocellulosic fillers stemming from agricultural residues has become an attractive strategy (Barkoula et al., 2010; Berthet et al., 2016; Berthet et al., 2017; Mousavioun et al., 2013; Lammi et al., 2018b). 
Olive pomace (OP) is an agro-waste that has already been combined with PHBV to produce biocomposites (Berthet et al., 2015; Dufresne et al., 2003; Hassaini et al., 2017; Lammi et al., 2018b). OP is a solid lignocellulosic residue representing 30 to $40 \%$ of the olive oil extraction by-products. It is mainly composed of skin, pulp and fragments of crushed stone (Gharbi et al., 2014; Gómez-Muñoz et al., 2012). OP represents an important environmental issue mostly in Mediterranean countries where they are generated in huge quantities, reaching $2,881,500$ tons/year worldwide, in a short period of time (Ravindran and Jaiswal, 2016). Moreover, they cannot be used as agricultural spreading since susceptible to cause harmful impacts on the environment when let on soil. Such negative effects are mainly due to their high content in phenolic and lipidic constituents, organic acid, low $\mathrm{pH}$, relatively high salinity, which confer them phytotoxic and antimicrobial properties. They also may be contaminated by fungi, whose fungal toxins combined with polyphenolic compounds are resistant to bacterial degradation, and consequently makes OP a significant source of environmental pollution (Cardelli and Benitez, 1998; Gómez-Muñoz et al., 2012; Niaounakis and Halvadakis, 2004). For all the above considerations related to the waste management issues generated by olive pomace, there is an urgent need to explore alternatives to convert them into valuable resources.

To date, most of available studies dealing with the incorporation of OP in polymer matrices have specifically focused on the use of olive stone, which is a fraction very rich in cellulose. In a previous study, it has been demonstrated that the use of either the whole OP or a pulprich fraction, richer in lignin, could be interesting in terms of final performance of materials (Lammi et al., 2018b). A better preservation of mechanical characteristics was achieved in the case of pulp-rich filler (PF), due to better filler/matrix interactions and hence higher interfacial adhesion. A range of water vapor and oxygen permeabilities could be reached, which makes it possible to consider the use of OP-based biocomposites as food packaging 
(rigid trays) for various types of food products, but also for horticulture applications. However, it has never been checked if the presence of lignin could have a negative impact on the biodegradability of resulting composite materials.

In this context, the objective of the present work is to investigate for the first time the impact of the composition of OP fillers on the capability of PHBV/OP-based biocomposites to biodegrade in soil. This is of prime importance since such materials are intended to be used to short-term use applications, such as pots or trays. For that purpose, three types of fillers displaying contrasted biochemical composition have been produced by following a dry fractionation process already reported by Lammi et al., 2018a, i.e. a stone-rich filler, a pulprich filler and a filler produced from the whole OP residue. PHBV/OP-based biocomposites were prepared by thermomolding, with filler content up to $15 \mathrm{wt} \%$. Biodegradation was evaluated through respirometric tests conducted in soil, at $28^{\circ} \mathrm{C}$ and in aerobic conditions during 4 months. The biodegradation rate of the different OP fractions and the resulting PHBV-based composites was discussed in relation to the material structure, as well as to the antibacterial activity of the OP samples assessed by a direct contact technique on solid medium.

\section{Materials and methods}

\subsection{Materials}

Olive pomace (OP) was kindly supplied by a local olive producer in the region of Azeffoun (Tizi-Ouzou, north-center of Algeria). It was obtained from the olive oil extraction of the Chemlal variety. Raw olive pomace was dried in an oven at $60^{\circ} \mathrm{C}$ for 24 hours before further usage.

A commercial grade of polyhydroxy-(butyrate-co-valerate) (PHBV) containing 3\% of valerate was purchased from NaturePlast (France) in the form of pellets (PHIO02 grade). 
Sulfuric acid, arabinose, xylose and glucose (Sigma-Aldrich), formamide, diiodomethane (Acros Organics, Geel, Belgium), ethylene glycol (Aldrich chemical Co. Inc., Milwaukee, USA) and glycerol (Merck, Darmstadt, Germany) were used for characterization of OP fillers. Barium chloride-Dihydrat (VWR Chemicals, Germany), sodium hydroxide (Grosseron, France), thymolphtalein (Alfa Aesar, Germany), hydrochloric acid and microcrystalline cellulose (Merck, Germany) were used for biodegradation tests.

\subsection{Preparation and characterization of olive pomace-based fillers}

Pulp-rich and stone-rich fractions were isolated from the raw olive pomace sample by dry fractionation with friction solicitations in a ball mill, as described by Lammi et al. (2018a). resulting fractions were then sieved and reduced in size using successive dry grinding steps (Lammi et al., 2018a). The obtained powders, i.e. the pulp-rich fraction (PF), the stone-rich fraction (SF) and the crude OP fraction (F0), displayed a median apparent diameter of respectively 55, 59 and $85 \mu \mathrm{m}$ (Lammi et al., 2018b).

The cellulose, hemicellulose and lignin contents of OP-based fillers were characterized in a two-stage acid hydrolysis. The first hydrolysis was carried out using a $72 \mathrm{wt} \% \mathrm{H}_{2} \mathrm{SO}_{4}$ solution at $30^{\circ} \mathrm{C}$ for 1 hour, while the second one was performed using a $4 \mathrm{wt} \% \mathrm{H}_{2} \mathrm{SO}_{4}$ solution at $121^{\circ} \mathrm{C}$ for 1 hour following the protocol described by Barakat et al. (2014). The lignin content was determined by the Klason method (Nicholson et al., 2014). The protein content was estimated according to the formula ( $\mathrm{N}$ x 6.25) (Jones, 1941), after the determination of nitrogen content $(\mathrm{N})$ by elementary analysis. The moisture content was determined by drying about two grams of sample in an oven at $110^{\circ} \mathrm{C}$ until reaching weight equilibrium. The ashes content was obtained by igniting about one gram of sample in a muffle furnace at $600^{\circ} \mathrm{C}$ for 5 hours. pH measurements were carried out with a pH electrode (VWR 1100L, Germany) on an aqueous suspension (five grams of sample mixed with $50 \mathrm{~mL}$ of distilled water) put under 
magnetic stirring during 30 min (Haddadin et al., 2009). All the analyses were performed in triplicate.

\subsection{Preparation and characterization of OP/PHBV-based biocomposites}

PHBV pellets and OP-based fillers (15 wt $\%)$ were blended in a HAAKE Rheomix internal mixer operating at a rotor speed of $60 \mathrm{rpm}$ and $170^{\circ} \mathrm{C}$ during $5 \mathrm{~min}$. Obtained compounds were cooled to room temperature and then, ground in a knife mill (SM 300, Retch, Germany) at a speed of $2200 \mathrm{rpm}$ through a $4 \mathrm{~mm}$ grid to obtain composite pellets. Compounds were dried at $60^{\circ} \mathrm{C}$ for at least 8 hours before the preparation of materials. Biocomposite films (10.5 $\mathrm{cm}$ wide squares, average thickness about $250 \mu \mathrm{m})$ were prepared by hot pressing the pellets between two Teflon coated plates at $170^{\circ} \mathrm{C}$, using a hydraulic thermopress (PLM $10 \mathrm{~T}$, Techmo, Nazelles, France). Samples were first allowed to melt for $3 \mathrm{~min}$. Then, a pressure of 150 bars was applied for $2 \mathrm{~min}$. The films were cooled at room temperature before being removed from the mould.

The percentage of carbon of OP fillers, neat PHBV, biocomposites and microcrystalline cellulose was determined using an elemental analyzer Vario Micro Cube (Elementar, Germany).

The surface morphology of the OP-fillers and the cross-section of the PHBV-based films (obtained after cryo-fracturing under liquid nitrogen) were observed by scanning electron microscopy (SEM) using a scanning electron microscope (SEM S-4500, Hitachi, Japan) with an acceleration voltage of $2 \mathrm{kV}$ and a detector for secondary electrons. The samples were previously coated with gold/palladium by ion beam sputtering.

Antibacterial tests were carried out to evaluate the antibacterial effect of both fillers and composites films following the direct contact technique on Mueller-Hinton agar against two 
selected bacterial strains (Staphylococcus aureus CIP 53156 and Escherichia coli 55B5 CIP 52170). The tests were performed on young pre-cultures of both bacteria in a Mueller-Hinton broth. Bacterial suspensions turbidity was standardized to 0.5 McFarland. The OP-based fillers (in the form of powders) were deposited in wells of $10 \mathrm{~mm}$ in diameter obtained with a piece-cutter on the agar medium. In the case of materials, discs of $10 \mathrm{~mm}$ diameter precut from the composite films were putted on the surface of the agar previously inoculated with the target bacteria. The incubation of Petri dishes was carried out at $30^{\circ} \mathrm{C}$ for 24 hours. The occurrence of an antibacterial effect of both materials was evidenced by the appearance a clear inhibition zone around the wells/discs.

\subsection{Biodegradation tests}

Respirometric tests were conducted in aerobic conditions to evaluate the biodegradation rate of OP-based fillers, PHBV matrix and PHBV/OP based biocomposites in soil medium. The method was adapted from the US standard ASTM D5988-96, which is a Standard Test Method for Determining Aerobic Biodegradation in Soil of Plastic Materials. The released $\mathrm{CO}_{2}$ being proportional to the percentage of biodegraded substrate, the $\mathrm{CO}_{2}$ evolution measures ultimate degradation (i.e. mineralization) in which a substance is broken down to its final products. Beforehand, film samples were frozen under liquid nitrogen and then ground with a domestic grinder (Moulinex type DPA1, France) to obtain particles around 1-2 mm.

The soil used in this study was taken from the park of the University of Montpellier (France) in April 2017, after removal of the superficial vegetation layer. The big pebbles and foreign objects were removed manually to obtain a homogeneous sample. The soil was dried in open air for one week and then sieved through a $2 \mathrm{~mm}$ mesh. The total dry solids content was determined by drying the soil at $105{ }^{\circ} \mathrm{C}$ until a constant weight. Soil characteristics were as follows: pH $6.8\left(\mathrm{H}_{2} \mathrm{O}\right), 2.3 \mathrm{wt} \%$ of organic matter, $16.85 \mathrm{wt} \%$ of clay, $26.85 \mathrm{wt} \%$ of lime and $56.3 \mathrm{wt} \%$ of sand. 
Biodegradation tests were carried out in cylindrical hermetic glass vessels (1000 mL capacity) containing three small open polypropylene flasks (60 mL capacity) as described by Chevillard et al. (2012). The first flask contained $25 \mathrm{~g}$ of dry soil mixed with samples whose weight corresponded to $50 \mathrm{mg}$ of carbon. The water content of soil samples was adjusted to reach $80 \%$ of the soil water retention capacity $(410 \mu 1 / \mathrm{g}$ wet basis). The second flask contained 10 $\mathrm{mL} \mathrm{NaOH}$ solution $(0.1 \mathrm{M})$ to trap the $\mathrm{CO}_{2}$ produced by microorganisms. The third flask contained distilled water, in order to maintain the relative humidity at $100 \%$ inside the vessel. The glass vessels were hermetically closed and incubated in the dark at $28 \pm 1^{\circ} \mathrm{C}$. Every week, glass vessels were open to ensure the back titration of the excess of $\mathrm{NaOH}$, which has not reacted with $\mathrm{CO}_{2}$. Before titrating the residual $\mathrm{NaOH}$ with $\mathrm{HCl}$ solution $(0.1 \mathrm{M})$ in the presence of thymophthaleine $0.10 \%$ (prepared in ethanol $95.5 \%(\mathrm{v} / \mathrm{v})), 5 \mathrm{~mL}$ of barium chloride solution $(20 \%(\mathrm{w} / \mathrm{v})$ in water) were added in each flask to precipitate carbonate ions. The flasks containing soil were weighted and appropriate amount of water was added in order to keep constant the water content initially fixed at $80 \%$ of the soil water retention capacity. During this procedure, the glass vessels were left open during 2 min in order to be aerated. At each dosage, a new flask containing $10 \mathrm{~mL} \mathrm{NaOH}(0.1 \mathrm{M})$ was placed in each glass vessel before being closed and put in the dark at $28^{\circ} \mathrm{C}$ until the next measurement. Biodegradation experiments included control and blank samples. The control samples were microcrystalline cellulose, a positive reference material well known for its biodegradation properties. The blank samples corresponded to the soil alone, without any addition of an external carbon source to measure both the $\mathrm{CO}_{2}$ produced by the soil carbon substrate and the $\mathrm{CO}_{2}$ present in the air of the glass vessel. All experiments were run in triplicate.

Results were calculated by subtracting the $\mathrm{CO}_{2}$ production of the blank. The theoretical maximum $\mathrm{CO}_{2}$ potential $\left(\mathrm{CO}_{2} \max (\mathrm{mg})\right)$ produced by total oxidation of the material is calculated using the following equation: 


$$
\mathrm{CO}_{2 \max }=\mathrm{Cx} \frac{44.01}{12.01}(\text { equation } 1)
$$

Where $\mathrm{C}$ is the amount of carbon of the sample introduced in the soil for the test (mg).

The percentage of biodegradation (B) is calculated by equation (2):

$$
\mathrm{B}=\frac{\mathrm{CO} 2 \text { material }-\mathrm{CO} 2 \text { blank }}{\mathrm{CO} 2 \max }(\text { equation } 2)
$$

As required by the ASTM D5988-96 standard, cellulose is used as a reference substance in order to check the activity of the soil and its biodegradation percentage should be higher than $70 \%$ after six months. Otherwise, the test must be regarded as invalid and should be repeated using another fresh soil.

The experimental degradation data were modeled with the Hill equation:

$$
\operatorname{Deg}=\operatorname{Deg}_{\max } \cdot \frac{t^{n}}{\left(k^{n}+t^{n}\right)} \quad(\text { equation } 3)
$$

where Deg [\%] is the percentage of degradation at time $\mathrm{t}$ [days], Degmax [\%] the percentage of degradation at infinite time, $\mathrm{k}$ [days], the time for which $\operatorname{Deg}=1 / 2 \operatorname{Deg}_{\max }$ and $\mathrm{n}$ the curve radius of the sigmoid function.

\section{Results and discussion}

\subsection{Biodegradability of OP-based fillers}

Respirometric tests were used to evaluate the degree and rate of aerobic biodegradation of OP-based fillers and related PHBV composites in contact with soil. $\mathrm{CO}_{2}$ evolution provides an indicator of the ultimate biodegradability ascribed to the mineralization of the test samples. The biodegradation kinetic of the three OP-based fillers and corresponding Hill parameters are presented in Figure 1 and Table 1, respectively. Respirometric tests conducted in the present study were validated since the biodegradation rate of micronized cellulose selected here as a reference material, reached $70 \%$ after only 45 days, while this threshold should be 
obtained in less than 183 days (6 months) to consider the test as valid according to the requirements of ASTM D5988-96 standard.

The characteristic Hill sigmoidal shape of the biodegradation curves is known to reflect the two phases commonly ascribed to the polymer degradation process involving microorganisms. Firstly, the polymer chains are cleaved in small fragments due the action of extracellular enzymes, and then, these latter are transported into the cell where they are ultimately mineralized mainly in $\mathrm{CO}_{2}$, water vapour, minerals, and biomass (Bastiolli, 2005).

As compared to cellulose known to rapidly biodegrade in soil, all the OP-based fillers biodegraded rather well, ranking as follows $\mathrm{F} 0<\mathrm{SF}<\mathrm{PF}$, with a biodegradation threshold superior to $70 \%$ (relative to cellulose) reached in 65,43 and 37 days respectively. As evidenced in Table 1, they all reached their rate of maximal degradation (Time rate max ) in less than 20 days, and it took less than 6 months for F0 and SF samples to reach $50 \%$ of $\mathrm{Deg}_{\max }$ as indicated by $k$ values. Regarding the pulp-rich fraction (PF), which exhibited the highest maximum rate of biodegradation (with a Degrate max value twice higher than these observed for the two others fillers), it is worth noting that this sample displayed a peculiar biodegradation curve shape reflected by a low radius of the sigmoid function.

\section{Figure 1.}

\section{Table 1.}

The biodegradation curve of the stone-rich fraction (SF) was almost superimposed on that of the cellulose reference, which could be ascribed to its richer cellulose content as compared to the other fillers (around 10, 12 and 17\% for PF, F0 and SF respectively) (Table 2). Contrary to our expectations, the highest rate of biodegradation was recorded for the pulp-rich sample (PF), despite its highest lignin content (48.9 wt\%) as compared to F0 (44.2 wt\%) and SF (37.7 wt\%) samples (Table 2). Indeed, lignin is a complex polyphenolic polymer that is known for 
its resistance to microbial degradation (Dashtban et al., 2010; Singh et al., 2016; Taherzadeh and Karimi, 2008). Furthermore, the biodegradation rate of organic substances was demonstrated to follow this order: carbohydrates $>$ hemicellulose $>$ cellulose $>$ lignin (Cooperband, 2002). In addition, as already evidenced by contact angle measurements (Lammi et al., 2018b), lignin was shown to confer a greater hydrophobicity to the PF fraction compared to the other OP-based ones. Thus, the hydrophobic character of PF should theoretically have reduced its affinity for soil water and therefore its contact with microorganisms. As a consequence, another reason is here proposed to explain the highest biodegradation rate displayed by the pulp-rich fraction $(\mathrm{PF})$, related to the higher protein content of PF (8.7\%) than the one of F0 (4.9\%) and SF (0.6\%) (Table 2). Recent researches have highlighted that factors such as organic carbon $(\mathrm{C})$, nitrogen $(\mathrm{N})$ content and carbon to nitrogen ratio $(\mathrm{C} / \mathrm{N})$ could be key elements to improve the biodegradation process, since they ensure optimal conditions for the growth and development of microbial communities involved in the decomposition of organic matter (De Bertoldi et al., 1983; Muktadirul Bari Chowdhury et al., 2013). Indeed, the optimal $\mathrm{C} / \mathrm{N}$ ratio generally found in a compost medium ranged from 25 to 35 , since it is assumed that microorganisms require 30 parts of $\mathrm{C}$ per unit of $\mathrm{N}$ for the composting process. Medium exhibiting high $\mathrm{C} / \mathrm{N}$ ratios are known to delay the composting process due to a surplus of degradable substrate for the microorganisms (Bishop Godfrey, 1983). In the soil medium used in the present study, SF sample exhibited a C/N ratio of about 555 against 37 and 65 for PF and F0 respectively (Table 2), which may explain the fact that PF biodegraded at a higher rate than F0 and SF.

Given that the crude OP sample (F0) consisted of a mixture of the pulp and stone tissues, composed of about $31 \%$ of PF and $56 \%$ of SF (Table 2), it was expected to display an intermediate biodegradation kinetic. However, results showed that F0 exhibited a slower biodegradation rate than these two fractions. It is worth noting that all the samples underwent 
the same grinding route in such a way to obtain similar average particle sizes (Lammi et al., 2018b) (Figure 2). The slow biodegradation kinetic of F0 was probably due to a more complex organization of the lignocellulosic structure within the particles, making them less accessible to the soil microorganisms, as compared to the two other pure and contrasted fractions (PF and SF). As reported by Taherzadeh and Karimi (2008), lignin and hemicellulose contents could also influence the accessibility of surface for enzymatic attack. In the same context, Mais et al. (2002) indicated that milling could be employed to alter the inherent ultra-structure of lignocellulose and decrease the degree of crystallinity, and suggested that reducing the size of the material by milling would make it more amenable to enzymatic degradation. However, this hypothesis would deserve to be further explored and validated through crystallinity measurements since, in the present study, the physical treatments applied to mill the pomace fractions were probably too superficial and mild to induce such structural changes.

\section{Figure 2.}

\section{Table 2.}

After 123 days, the biodegradation rates reached 88.6, $111.8,117.2$ and $162.8 \%$ for F0, cellulose, SF and PF samples respectively (Figure 1A). Reaching biodegradation rate higher than $100 \%$ has already been reported and is known as priming effect. It generally occurs when the soil inoculum of the test reactor containing the samples produces more $\mathrm{CO}_{2}$ than the soil inoculum in the blank reactors. This peculiar behavior results from a stimulation of the organic matter mineralization due to easily decomposable organic matter that would be released in the medium during the biodegradation of specific materials. This phenomenon would arise from particular interactions occurring between the transformation of the added substances and the natural soil cycle of carbon (Kuzyakov et al., 2000). 
Based on our results, the biodegradation patterns of the OP-fillers (Figure 1A) did not support the different literature data reporting that crude olive pomace would be unable to biodegrade in soil, being consequently at the origin of environmental pollution. According to Cardoso et al. (2005), the phenolic compounds being not degraded during olive oil extraction, olive pomace, like olive pulp, would be expected to be a good source of those compounds.

To verify this assumption, antibiogram tests have been conducted on the OP-based fillers using two targeted bacterial strains ( $S$. aureus and E. coli). No antibacterial activity was evidenced, as clearly shown in Figure 3 by the absence of bacterial growth inhibition zone around the wells of the different samples. The dark color was due to the diffusion of chlorophyll pigments in Mueller-Hinton agar. These pigments responsible for the olive fruit color were more concentrated in the particles of F0 and PF powders, as already demonstrated by Lammi et al. (2018a). Even if these results appeared rather unexpected with respect to literature, they underpinned our biodegradation results. To explain the lack of antibacterial effect, it could be assumed that the preliminary stage consisting in the drying of the raw biomass for 24 hours at $60^{\circ} \mathrm{C}$ would cause a thermal denaturation of the active compounds resulting in a loss of any expected inhibiting effect. In addition, during the successive grinding operations, the various OP-based samples were exposed to frictional heating when in contact with grinder. Exposure to such a temperature increase would also contribute to denature the bioactive substances involved in the targeted antibacterial effect. To finish with, it cannot be excluded that the OP-based fillers were also probably already microbiologically contaminated. This contamination could occur after the drying of the crude pomace or during the grinding and sieving operations, both stages being done at room temperature in contact with the ambient air. These microorganisms might enhance the biodegradation of the OPbased fillers acting in cooperation with the soil microorganisms, both contributing to a faster biodegradation rate. 


\section{Figure 3.}

\subsection{Biodegradability of OP-based biocomposites}

342 The biodegradation kinetic of neat PHBV and OP/PHBV-based composites are presented in

343 Figure 4, and the respective Hill's parameters obtained by modeling experimental data 344 according to Hill equation are gathered in Table 1.

Neat PHBV exhibited slower degradation kinetic than OP/PHBV-based composites whatever the OP fraction used as filler. Hill's parameters clearly confirmed that incorporation of OP fillers up to $15 \mathrm{wt} \%$ in PHBV accelerated the biodegradation of the composite materials compared to the neat polymer. As indicated in Table 1, this latter recorded only $163 \%$ of degradation at infinite time and reached $50 \%(k)$ of this degradation after about 109 days. By contrast, all the OP-based composites exceeded 200\%, with $k$ values being reached in less than 85 days. It is interesting to note that the nature of the filler used had no significant influence on the degradation profile of composites. In fact, the neat PHBV matrix recorded the lowest rate of degradation with a maximum ( $\left.\mathrm{Deg}_{\text {rate max }}\right)$ reached after 95 days $\left(\right.$ Time $_{\text {rate }}$ $\left.{ }_{\max }\right)$ whereas all the composite formulations displayed twice the maximum degradation rate after only 68 days (Table 1).

Finally, 4 months of incubation at $28^{\circ} \mathrm{C}$ in the soil and under aerobic conditions, PHBV biodegradation reached $91 \%$ (i.e. about $83 \%$ relative to cellulose) without attaining the plateau of carbon dioxide released. This indicated that respirometric measurements should have been prolonged a few months more for PHBV without however questioning its biodegradability in soil. As claimed by the recent specification standard NF EN 17033, a biodegradation level of $90 \%$ relative to cellulose should be reached no later than 2 years. According to Boopathy (2000), biodegradation is dependent on a number of factors such as microbial activity of the environment, exposed surface area, temperature, $\mathrm{pH}$ and molecular 
weight. It is worth specifying that in the present study all the material samples were previously ground as particles around 1-2 mm before being tested. As a consequence, it could be attested that all the respirometric tests have been performed in the same standardized conditions, the results obtained being therefore comparable.

To conclude, the PHBV-based biocomposites could be considered as significantly much more biodegradable than the virgin PHBV matrix whatever the OP fractions used. Monitoring the evolution of the carbon dioxide over time through respirometric revealed that the biodegradation kinetics of the biocomposite materials followed the order: PHBV $<\mathrm{PHBV}$ $\mathrm{PF}<\mathrm{PHBV}-\mathrm{SF}<\mathrm{PHBV}-\mathrm{F} 0$. After 123 days of soil incubation, PHBV-PF and PHBV-SF formulations overpassed $134 \%$ of biodegradation, and the PHBV-F0 film exceeded $143 \%$. This peculiar behavior resulted from the priming effect already mentioned above for the OPfractions which all reached biodegradation rates greater than $100 \%$. This synergistic effect was certainly related to the presence of OP-fillers, which further boost the biodegradation process of the composites compared to the PHBV matrix alone. Biodegradation rates of biocomposites exceeding $100 \%$ have already been reported for films made of gliadins crosslinked by cinnamaldehyde (Balaguer et al., 2015), starch-polystyrene foams (Pushpadass et al., 2010), or L-polylactide-polycaprolactone co-polymer films (Plackett, 2006) under composting conditions.

\section{Figure 4.}

The increased biodegradability of composite materials might be the result of three concomitant effects. Firstly, it could be due to the increased hydrophilicity of biocomposites compared to virgin PHBV due to the incorporation of fillers that are much more hydrophilic than the matrix. This assumption was supported by results reported by Lammi et al. (2018b) indicating a significant increase of the water vapor permeability of PHBV films after 
introducing OP-fillers, and especially in the case of F0 and SF fractions. A higher hydrophilicity would favor the adsorption and then the transport of water within the composite material, which in turn would promote the microbial degradation of material (Chevillard et al., 2012).

Secondly, differences in biodegradation patterns between composite materials could be attributed to differences in the microstructure of materials. A poor affinity between the filler and the polymer matrix would result in a poor dispersion of the fillers and the formation of aggregates as well as a poor filler/matrix adhesion that would induce the creation of voids between the filler and the matrix. These two phenomena would lead to the creation of a bulk porosity and therefore to the creation of a preferential pathway for the transport of water within the composite material. Such microstructural defects would also be prone to increase the fragility of materials favoring their physical disintegration, and thus resulting in a higher contact surface for ensuring microorganisms colonization. This hypothesis was supported by the microstructural investigation of the composite materials characterized by SEM after cryofracture (Figure 5). Although PHBV cross-section displayed a homogeneous and smooth surface, contrariwise, the cross sections of PHBV-F0 and PHBV-SF films were rough, with the evidence of cracks and voids at the filler/matrix interface probably due to the debonding of fillers. As described above, this would allow microorganisms to attach and form biofilms colonizing the material surface. In the case of PHBV/PF composites, the particles were entirely wetted by the polymer matrix, indicating a good filler/matrix interfacial adhesion. This was attributed to the great affinity between PF fillers and PHBV matrix as confirmed by similar values of surface energy, previously demonstrated (Lammi et al., 2018b). This more homogenous and compact microstructure would hinder the diffusion of water and thus the accessibility to microorganisms, as compared to PHBV/F0 and PHBV/SF composites. As a 
consequence, PHBV-PF composite material biodegraded at a lower rate than the other composites containing F0 and SF fillers.

\section{Figure 5.}

Difference in crystallinity between the materials might also be at the origin of changes in their biodegradation patterns. Indeed, the kinetic of enzymatic degradation is known to depend on the overall crystallinity of the material (El-Hadi et al., 2002). An increase in polymer crystallinity is known to be detrimental for the polymer biodegradability since crystalline zones are less accessible for the microorganisms (Wei et al., 2015). Indeed, as previously demonstrated by the authors Lammi et al. (2018b), the presence of F0 and SF as fillers in the PHBV led to a decrease in the crystallinity degree $(X \mathrm{c})$ of the neat matrix whereas the crystallinity of the PHBV/PF was increased. The recorded degrees of crystallinity $X \mathrm{c}(\%)$ were 65, 68, 75 and 78\% for PHBV-F0, PHBV-SF, PHBV and PHBV-PF films, respectively (Lammi et al., 2018b). Such an anti-nucleating effect might contribute to facilitate the biodegradability of PHBV/F0 and PHBV/SF composites as compared to PHBV/PF. This phenomenon was previously observed for biocomposites based on polyhydroxybutyrate and fermentation residue coming from potato peel waste (Wei et al., 2015). In the case of the $\mathrm{PHBV} / \mathrm{PF}$ composite formulation, it is worth noting that the effect of the increased crystallinity was compensated by the opposite effect resulting from the increased hydrophilicity and the more heterogenous microstructure as compared to the neat PHBV matrix.

Finally, biodegradation performance of all the composite materials was underpinned by the antibiogram tests undertaken on composite films and neat PHBV chosen as control. As shown in Figure 3, no inhibition zone was evidenced around the different disks, which was in full agreement with their fast biodegradation in the soil medium. Such positive results enabled to 
envisage other routes for valorizing the different fractions stemming from olive pomace wastes and justified the approach consisting in introducing them as fillers for developing biodegradable composites based on PHBV.

\section{Conclusion}

The present work fits into a larger environmental context aiming at reducing the impact of the agro-residues by valorising them to design biodegradable materials. With a view to achieve a complete valorisation of olive pomace, all its components (including the constitutive tissues of the olive fruit, namely the pulp and the stone) were transformed in powders using a rationale dry fractionation process before being used as fillers to develop PHBV-based biocomposites. The impact of such fillers on the biodegradability in soil of the resulting composite materials was investigated in relation with their respective chemical composition. Results revealed that the incorporation of OP-based fillers in PHBV accelerated the biodegradation kinetics of the composites, which exceeded $100 \%$ after 4 months. These results were supported by measurements of crystallinity as well as SEM observations. Moreover, the absence of any antibacterial effect of both the olive pomace-based fillers and the resulting biocomposites towards the target bacteria (Staphylococcus aureus and Escherichia coli) confirmed the capability of such materials to biodegrade in soil and fully justified the relevance of this study. To conclude, this research presented a promising track for the valorisation of olive pomace through the elaboration of biocomposites materials that might be notably intended for short-term use such as packaging.

on the other hand, these results clearly showed the interest of crude OP fractionation and led us to propose another exploitation field for the SF and PF fractions as natural and biodegradable fertilizers for the agricultural grounds.

\section{Acknowledgments}


This research was supported by MALICE project co-financed by the European Regional

461 Development Fund, and the PNE Program (2016-2017) of the Algerian Ministry of Higher 462 Education and Scientific Research.

\section{References}

464

465

466

467

468

469

470

471

472

473

474

475

476

477

478

479

480

481

482

483

- Andrady AL. Microplastics in the marine environment: A review. Marine Pollution Bulletin, 2011; 62:1596-1605. DOI:10.1016.

- Avérous L, Pollet E. Chapter 2: Biodegradable Polymers. Environmental Silicate NanoBiocomposites, Green Energy and Technology, DOI: 10.1007/978-1-4471-4108-2-2, CSpringer-Verlag London, 2012.

- Balaguer MP, Villanova J, Cesar G, Gavara R, Hernandez-Munoz P. Compostable properties of antimicrobial bioplastics based on cinnamaldehyde cross-linked gliadins. Chemical Engineering Journal, 2015; 262: 447-455.

- Barakat A, Chuetor S, Monlau F, Solhy A, Rouau X. Eco-friendly dry chemo-mechanical pretreatments of lignocellulosic biomass: Impact on energy and yield of the enzymatic hydrolysis. Applied Energy, 2014; 113: 97-105.

- Barkoula NM, Garkhail SK, Peijs T. Biodegradable composites based on flax/polyhydroxybutyrate and its copolymer with hydroxyvalerate. Industrial Crops and Products, 2010; 31: 34-42.

- Bastioli C. Handbook of biodegradable polymers. Smithers Rapra Technology;2005.

- Berthet MA, Angellier-Coussy H, Guillard V, Gontard N.Vegetal fibre-based biocomposites: Which stakes for food packaging applications. Journal of Applied Polymer Science, 2016;133(2), SI (42528).

- Berthet MA, Angellier-Coussy H, Machado D, Hilliou L, Staebler A, Vicente A, Gontard N. Exploring the potentialities of using lignocellulosic fibers derived from three food by- 
products as constituents of biocomposites for food packaging. Industrial Crops Products, $485 \quad 2015 ; 69: 110-122$.

486

487

488

489

490

491

492

493

494

495

496

497

498

499

500

501

502

503

504

505

506

507

- Berthet MA, Mayer-Laigle C, Rouau X, Gontard N, Angellier-Coussy H. Sorting natural fibres: A way to better understand the role of fibre size polydispersity on the mechanical properties of biocomposites. Composites Part A, 2017; 95: 12-21.

- Bishop PL, Godfrey C. Nitrogen transformations during sludge composting. BioCycle, $1983 ; 24: 34-39$.

- Boopathy R. Factor limiting bioremediation technologies. Bioresource Technology, 2000;74: 63-67.

- Cardelli R, Benitez E. Changes of chemical properties in two soils amended with moist olive residues. Agricoltura Mediterranea, 1998; 128: 171-177.

- Cardoso S M, Guyot S, Marnet N, da-Silva J A L, Renard CMGC, Coimbra MA. Characterisation of phenolic extracts from olive pulp and olive pomace by electrospray mass spectrometry. Journal of the Science of Food and Agriculture, 2005; 85:21-32. DOI: $10.1002 /$ jsfa.1925.

- Chevillard A, Angellier-Coussy H, Guillard V, Gontard N, Gastaldi E. Investigating the biodegradation pattern of an ecofriendly pesticide delivery system based on wheat gluten and organically modified montmorillonites. Polymer Degradation and Stability, 2012; 97 : 2060-2068.

- Cooperband L. The Art and Science of Composting: A Resource for Farmers and Compost Producers. University of Wisconsin-Madison, 2002.

- Dashtban M, Schraft H, Syed TA, Qin W. Fungal biodegradation and enzymatic modification of lignin. Review Article. International Journal of Biochemistry and Molecular Biology, 2010;1(1):36-50. 
- De Bertoldi M, Vallini G, Pera A. The biology of composting: a review. waste manage research,19831: 157-176.

- Dufresne A, Dupeyre D, Paillet M. Lignocellulosic flour-reinforced poly(hydroxybutyrate-covalerate) composites. Journal of Applied Polymer Science, 2003;87: 1302.

- El-Hadi A, Schnabel R, Straube E, Müller G, Henning S. Correlation between degree of crystallinity, morphology, glass temperature, mechanical properties and biodegradation of poly(3-hydroxyalkanoate) PHAs and their blends. Polymer Testing, 2002; 21(6):665-674.

- Gharbi A, BelHassen R, Boufi S. Composite materials from unsaturated polyester resin and olive nuts residue: The effect of silane treatment. Industrial Crops and Products, 2014; 62: 491-498.

- Gómez-Muñoz B, Hatch D J, Bol R, García-Ruiz R. The Compost of Olive Mill Pomace: From a Waste to a Resource - Environmental Benefits of Its Application in Olive Oil Groves. Chapter from the book Sustainable Development - Authoritative and Leading Edge. Content for Environmental Management, 2012. http://dx.doi.org/10.5772/48244.

- Haddadin MSY, Haddadin Jb, Arabiyat OI, Hattar BA. Biological conversion of olive pomace into compost by using Trichoderma harzianum and Phanerochaete chrysosporium. Bioresource Technology, 2009;100: 4773-4782.

- Hassaini L, Kaci M, Touati N, Pillin I, Kervoelen A, Bruzaud S. Valorization of olive husk flour as a filler for biocomposites based on poly(3-hydroxybutyrate-co-3hydroxyvalerate): Effects of silane treatment. Polymer Testing, 2017;59: 430-440.

- Kourmentza C, Plácido J, Venetsaneas N, Burniol-Figols A, Varrone C, Gavala HN, Reis MAM. Recent Advances and Challenges towards Sustainable Polyhydroxyalkanoate (PHA) Production: a review. Bioengineering, 2017; 4, 55. DOI:10.3390/bioengineering 4020055 . 
- Kumar S, Das PM, Rebecca LJ, Sharmila S. Isolation and identification of LDPE degrading fungi from municipal solid waste. Journal of Chemical and Pharmaceutical Research, 2013; 5(3): 78-81.

- Kuzyakov Y, Friedel JK, Stahr K. Review of mechanisms and quantification of priming effects. Soil Biology and Biochemistry, 2000; 32: 1485-1498. DOI 10.1016/S00380717(00)00084-5.

- Lammi S, Barakat A, Mayer-Laigle C, Djenane D, Gontard N, Angellier-Coussy H. Dry fractionation of olive pomace as a sustainable process to produce fillers for biocomposites. Powder Technology, 2018a; 326: 44-53. DOI.org/10.1016/j.powtec.2017.11.060.

- Lammi S, Le Moigne N, Djenane D, Gontard N, Angellier-Coussy H. Dry fractionation of olive pomace for the development of food packaging biocomposites. Industrial Crops and Products, 2018b; 120: 250-261. DOI.org/10.1016/j.indcrop.2018.04.052

- Madison LL, Huisman GW. Metabolic engineering of poly(3-hydroxyalkanoates): from DNA to plastic. Microbiology and Molecular Biology Reviews, 1999; 63(1): 21-53.

- Mais U, Esteghlalian AR, Saddler JN, Mansfield SD. Enhancing the enzymatic hydrolysis of cellulosic materials using simultaneous ball milling. Applied Biochemistry and Biotechnology, 2002; 98:815-832.

- Mousavioun P, Halley PJ, Doherty WOS. Thermophysical properties and rheology of PHB/lignin blends. Industrial Crops and Products, 2013;50: 270-275.

- Muktadirul Bari Chowdhury AKM, Akratos CS, Vayenas DV, Pavlou S. Olive mill waste composting: A review. International Biodeterioration \& Biodegradation, 2013;85: 108119.

- Niaounakis M, Halvadakis CP. Olive-Mill Waste Management, first ed. Typothito-George Dardanos, Athens. 2004. 
- Nicholson DJ, Leavitt AT, Francis RC. A three-stage klason method for more accurate determinations of hardwood lignin content. Cellulose Chemistry and Technology, 2014; 48 (1-2): 53-59.

- NF EN 17033 : 2018, Plastiques — Films de paillage biodégradables thermoplastiques pour utilisation en agriculture et horticulture - Exigences et méthodes d'essai

- Plackett DV, Holm VK, Johansen P, Ndoni S, Nielsen PV, Sipilainen-Malm T, Sodergard A, Verstichel S. Characterization of L-polylactide and L-polylactide-polycaprolactone copolymer films for use in cheese-packaging applications. Packaging Technology and Science, 2006; 19:1-24.

- Pushpadass HA, Weber RW, Dumais JJ, Hanna MA. Biodegradation characteristics of starch-polystyrene loose-fill foams in a composting medium. Bioresource Technology, 2010; 101: 7258-7264.

- Ravindran R, Jaiswal AK. Exploitation of food industry waste for high-value products. Trends in Biotechnology, 2016; 34: 58-69.

- Singh R, Kumar M, Mittal A, Mehta PK. Lignocellulolytic enzymes: Biomass to biofuel. International Journal of Advanced Research, 2016; 4(10): 2175-2182. DOI: 10.21474/IJAR01/2039.

- Singh Saharan B, Grewal A, Kumar P. Biotechnological Production of Polyhydroxyalkanoates: A Review on Trends and Latest Developments. Chinese Journal of Biology, 2014: 1-18. http://dx.doi.org/10.1155/2014/802984.

- Stoleru E, Hitruc EG, Vasile C, Opric L. Biodegradation of poly(lactic acid)/chitosan stratified composites in presence of the Phanerochaete chrysosporium fungus. Polymer Degradation and Stability, 2017; 143: 118-129. 
- Taherzadeh MJ, Karimi K. Pretreatment of Lignocellulosic Wastes to Improve Ethanol 581 and Biogas Production: A Review. International Journal of Molecular Sciences, 2008; 9: $582 \quad 1621-1651$.

583 - Tokiwa Y, Calabia BP, Ugwu CU, Aiba S. Biodegradability of Plastics: Review.

$584 \quad$ International Journal of Molecular Sciences, 2009; 10: 3722-3742.

$585 \quad$ DOI:10.3390/ijms10093722.

586

- Wei L, Liang S, McDonald AG. Thermophysical properties and biodegradation behavior of green composites made from polyhydroxybutyrate and potato peel waste fermentation residue. Industrial Crops and Products, 2015; 69: 91-103. 


\section{Figure Captions.}

Figure 1. Kinetic of biodegradation (A) and biodegradation rate (B) of OP-based fillers in sol.

Figure 2. SEM pictures of olive pomace-based fillers (scale bar $=300 \mu \mathrm{m}$ ).

Figure 3. Antibiogram results of OP-based fillers and OP-based composites after incubation at $37^{\circ} \mathrm{C}$ during $24 \mathrm{~h}$.

Figure 4. Kinetic of biodegradation (A) and biodegradation rate (B) of OP/PHBV-based composites in sol.

Figure 5. SEM pictures of OP/PHBV-based biocomposites surfaces (x 500: scale bar $=60$ $\mu \mathrm{m}, \mathrm{x}$ 1000: scale bar $=30 \mu \mathrm{m})$. 
Figures.

Figure 1.
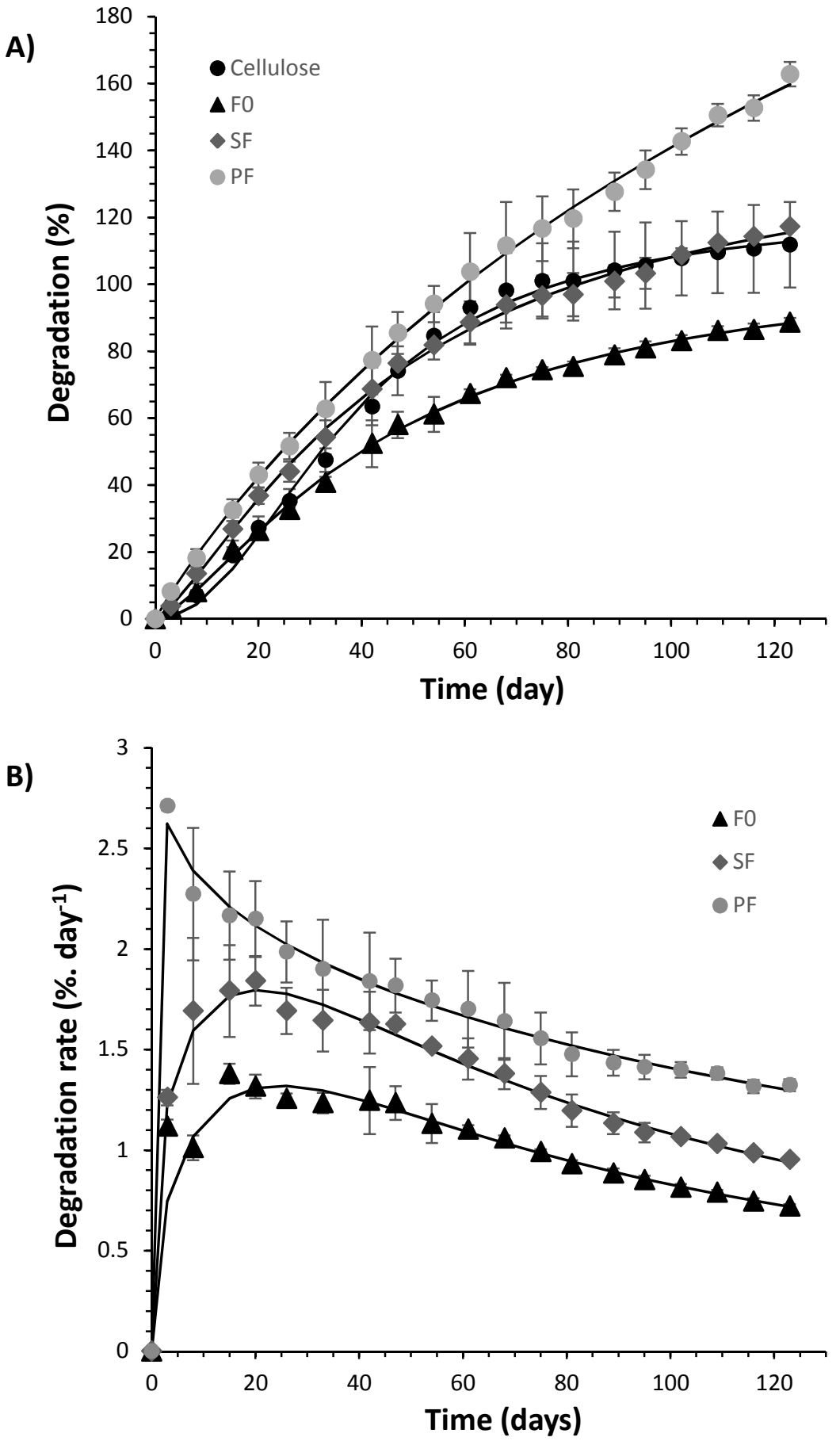
Figure 2.
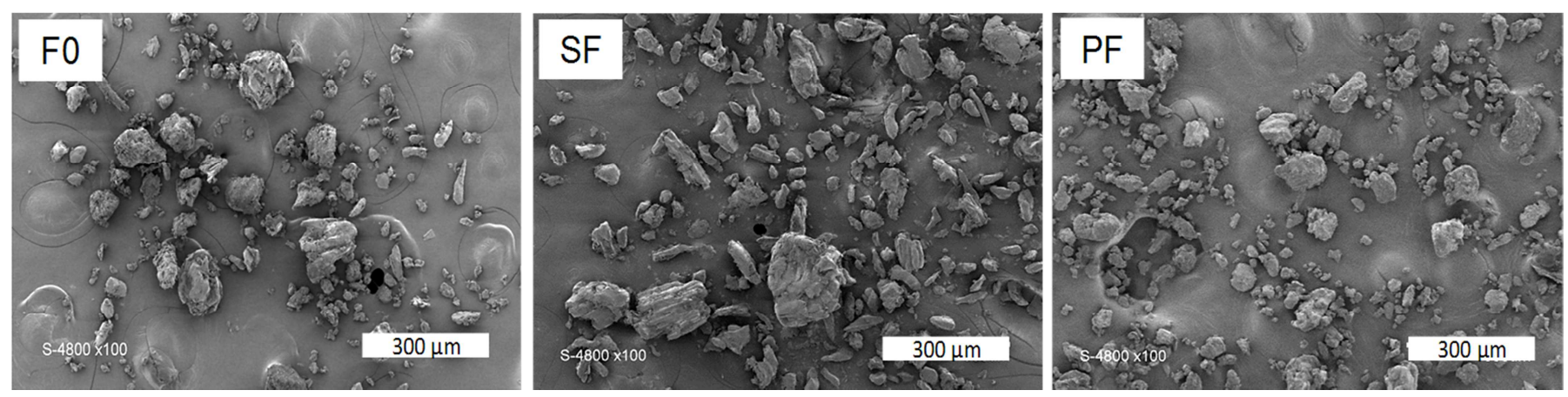
Figure 3.

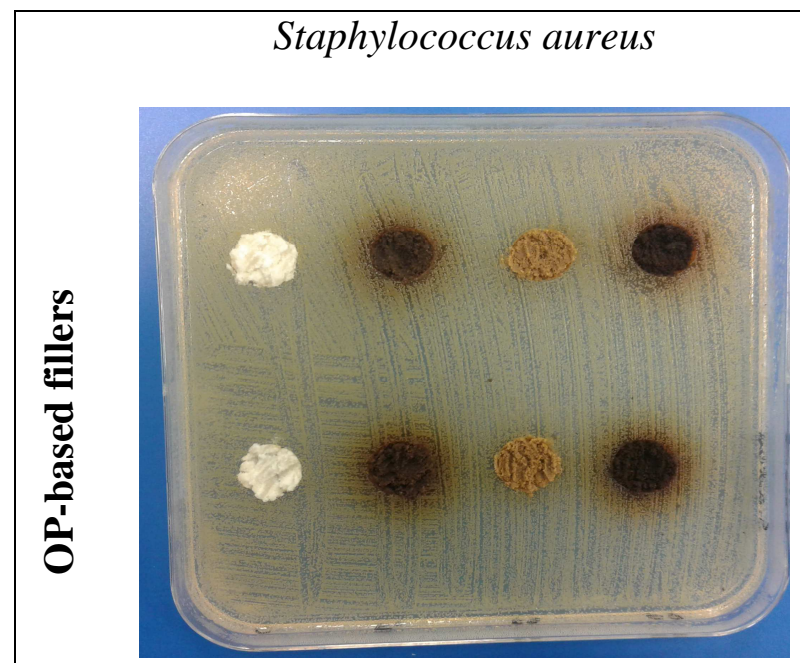

Escherichia coli

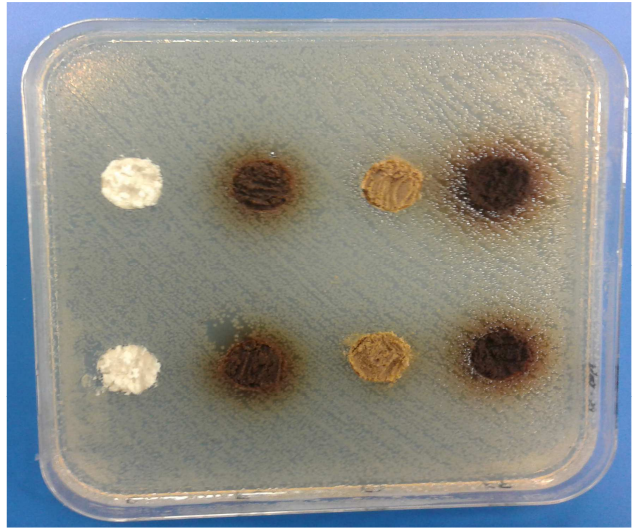

From left to right: cellulose (negative control), F0, SF and PF
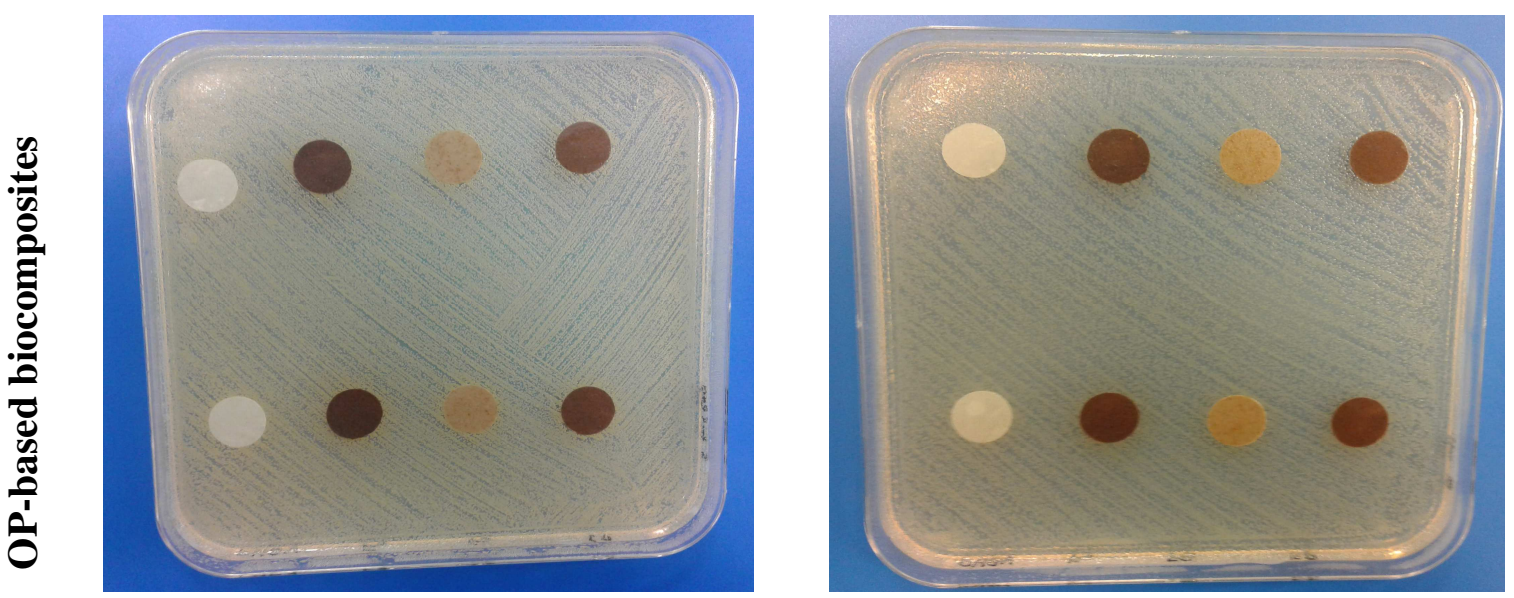

From left to right: PHBV (negative control), PHBV-F0(15\%), PHBV-SF(15\%) and PHBV-PF $(15 \%)$ 
Figure 4.

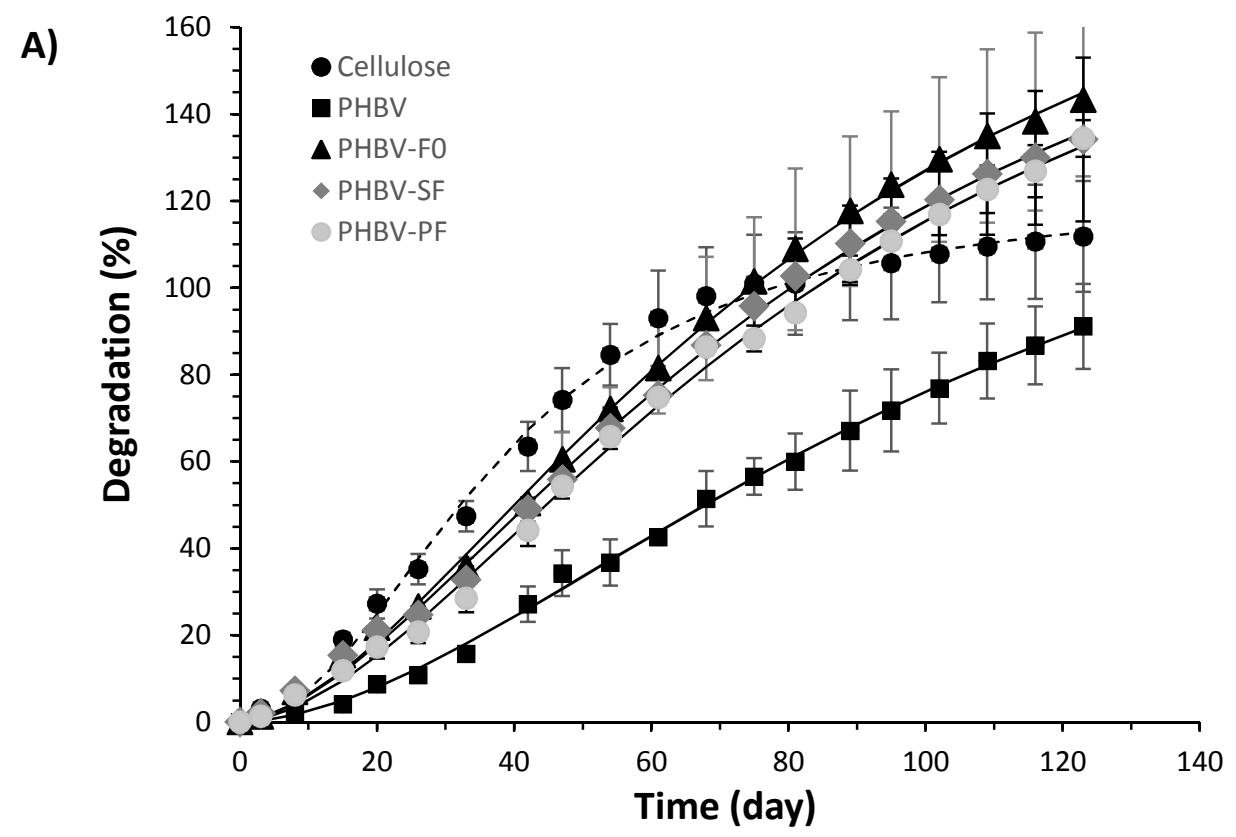

B)

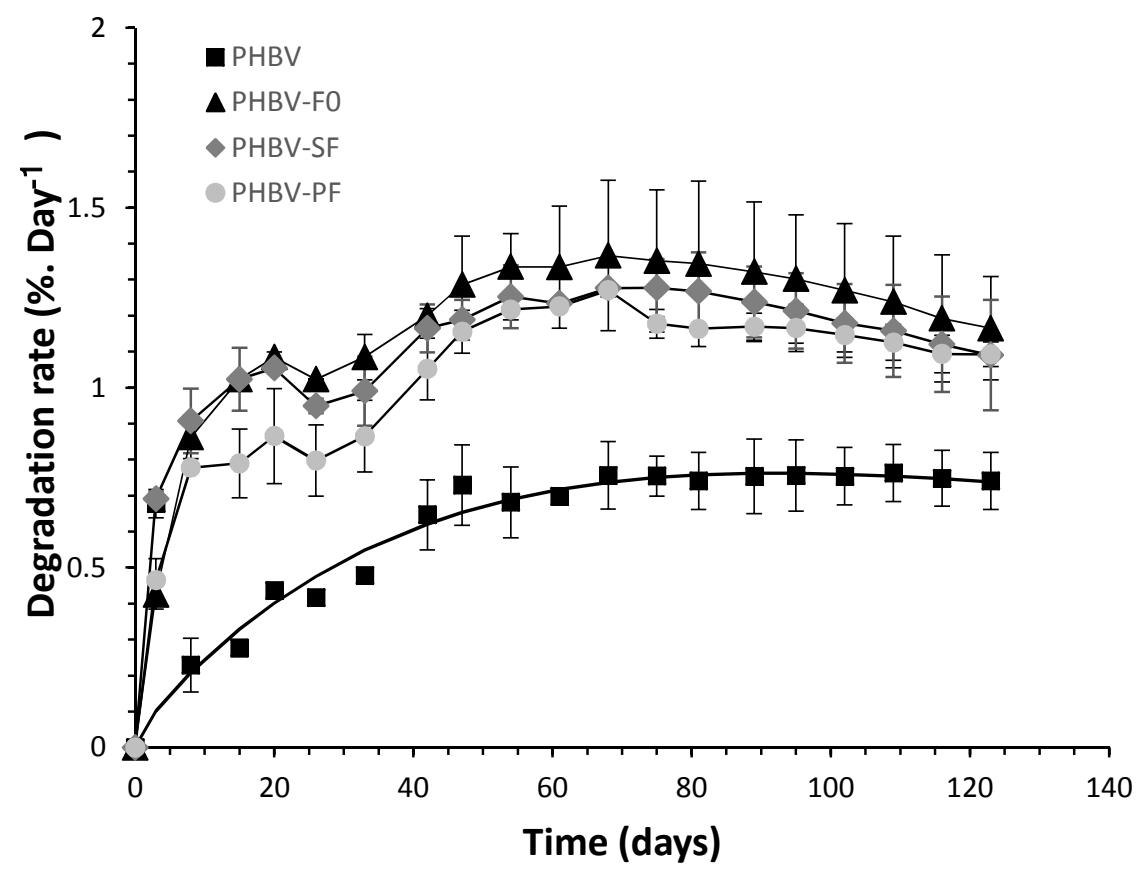


Figure 5.

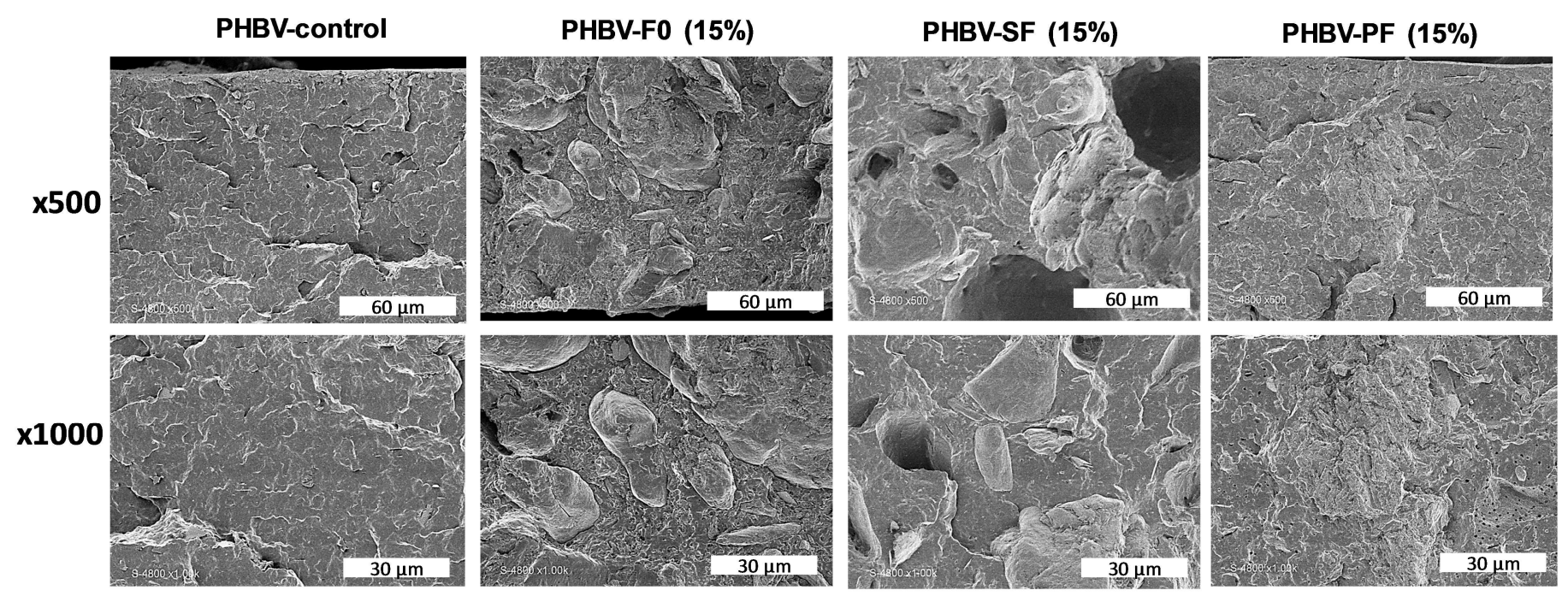


Tables.

Table 1: Hill parameters (Deg $\left.\max _{\max }, k, n\right)$ and related biodegradation indicators (Time $_{\text {rate max }}$, Deg rate max $)$ of OP-based fillers and OP/PHBV-based composites in respirometric test.

\begin{tabular}{|c|c|c|c|c|c|c|}
\hline \multirow[t]{2}{*}{ Sample } & \multicolumn{4}{|c|}{ Hill parameters } & \multirow{2}{*}{$\begin{array}{c}\text { Time }_{\text {rate max }} \mathrm{b} \\
\text { [days] }\end{array}$} & \multirow{2}{*}{$\begin{array}{l}\text { Deg }_{\text {rate max }} \\
{\left[\% \text { day }^{-1}\right]}\end{array}$} \\
\hline & $\operatorname{Deg}_{\max }{ }^{a}[\%]$ & $k$ [days] & $n$ & $R^{2}$ & & \\
\hline Control(cellulose) & $122( \pm 3.1)$ & $38.2( \pm 1.3)$ & $2.1( \pm 0.1)$ & 0.99 & 42 & 1.6 \\
\hline F0 & $109( \pm 3.0)$ & $44.9( \pm 2.1)$ & $1.4( \pm 0.0)$ & 0.99 & 15 & 1.3 \\
\hline SF & $147( \pm 5.6)$ & $46.7( \pm 3.2)$ & $1.3( \pm 0.0)$ & 0.99 & 20 & 1.8 \\
\hline $\mathrm{PF}$ & $426( \pm 66.5)$ & $213.1( \pm 60.9)$ & $0.9( \pm 0.0)$ & 0.99 & 3 & 2.6 \\
\hline PHBV & $163( \pm 15.5)$ & $108.2( \pm 11.5)$ & $1.7( \pm 0.1)$ & 0.99 & 95 & 0.7 \\
\hline PHBV-F0(15\%) & $219( \pm 12.0)$ & $82.6( \pm 5.8)$ & $1.7( \pm 0.1)$ & 0.99 & 68 & 1.3 \\
\hline PHBV-SF $(15 \%)$ & $209( \pm 14.3)$ & $84.9( \pm 7.5)$ & $1.6( \pm 0.1)$ & 0.99 & 68 & 1.3 \\
\hline PHBV-PF(15\%) & $204( \pm 15.7)$ & $85.6( \pm 8.1)$ & $1.7( \pm 0.1)$ & 0.99 & 68 & 1.2 \\
\hline
\end{tabular}

Values in parentheses represent the confident intervals.

${ }^{\mathrm{a}} \mathrm{Deg}_{\max }$ : percentage of degradation at infinite time;

$k$ : constant of the Hill equation representing the time for which Deg $=1 / 2 \operatorname{Deg}_{\max }$;

$\mathrm{n}$ : constant of the Hill equation representing the curve radius of the sigmoid function.

${ }^{\mathrm{b}}$ Time $_{\text {rate max }}$ : time to reach the maximum biodegradation rate.

${ }^{c} D g_{\text {rate max }}$ : maximum degradation rate. 
Table 2: Biochemical composition (\% dry basis) of olive pomace fractions

\begin{tabular}{|c|c|c|c|c|c|c|c|c|c|c|}
\hline & Yield & $\mathrm{pH}$ & Humidity & Ashes & Cellulose & Hemicellulose & Lignin & Proteins & $\mathrm{C}$ & $\mathrm{N}$ \\
\hline F0 & 100 & $4.9 \pm 0.0$ & $4.5 \pm 0.0$ & $2.6 \pm 0.2$ & $12.8 \pm 3.1$ & $11.9 \pm 2.6$ & $44.2 \pm 4.3$ & 4.9 & 51.07 & 0.78 \\
\hline $\mathrm{SF}$ & 56.4 & $4.9 \pm 0.0$ & $3.3 \pm 0.0$ & $0.8 \pm 0.0$ & $17.4 \pm 1.1$ & $18.5 \pm 0.4$ & $37.7 \pm 3.4$ & 0.6 & 49.97 & 0.09 \\
\hline $\mathrm{PF}$ & 31.3 & $5.0 \pm 0.0$ & $7.2 \pm 0.0$ & $4.6 \pm 0.1$ & $10.8 \pm 0.9$ & $7.9 \pm 0.4$ & $48.9 \pm 5.9$ & 8.7 & 52.05 & 1.38 \\
\hline
\end{tabular}

